\title{
Digital Feminist Activism: \#MeToo and the everyday experiences of challenging rape culture
}

\author{
Kaitlynn Mendes, University of Leicester \\ Jessica Ringrose, University College London
}

"The world should know that we face harassment everywhere." - MeToo Survey Respondent

In October 2017, we as a research team were moved by the flood of experiences and messages of support, solidarity, sadness, anger and outrage that emerged around \#MeToo through our own social media accounts. Although initially surprised by the global attention garnered by the \#MeToo movement, the fact survivors took to social media to share experiences of sexual violence and engage in a "call-out culture" resonated strongly with our ongoing research. Since 2014, we have been studying the broad terrain of "digital feminist activism", and the public's growing willingness to engage with resistance and challenges to sexism, patriarchy and other forms of oppression via feminist uptake of digital communication (see for instance, Mendes et al., 2019). Although there is much research underway on the \#MeToo movement and other forms of digital feminist activism (see Fischer, 2016; Fotopoulou, 2016), few to date have collected empirical data from participants in these movement themselves. In this sense, while there has been a growth of scholarship examining how feminists are using digital media technologies, little is known about the complexities inherent in doing digital feminist activism, which may be overlooked, hidden or invisible via textual media analyses alone (for exceptions see Fileborn, 2017, 2018; Keller et al., 2018; Ringrose \& Mendes, 2018). 
Drawing on a thematic analysis of original empirical data gathered from 117 qualitative surveys responses from \#MeToo users, as well as further in-depth interviews with six of these respondents, this chapter interrogates the everyday experiences of those who have participated in the \#MeToo campaign. In doing so, we unpack the complex range of motivations underpinning participation in this media event, drawing attention to issues of power and privilege in the ways certain testimonies are listened to, ignored or (dis)believed (see also Huda, Cowan \& Jawad; Ryan; \& Ison, this collection). Throughout the chapter, we challenge generalizations that engaging in digital activism is easy, banal, or a form of "lowintensity" activism, and instead highlight the often traumatic, emotionally exhausting and affective nature of this work. We conclude by pointing to the ways that involvement in digital feminist campaigns such as \#MeToo transforms many of our participants' lives in both tangible and hard-to-measure ways.

As a qualitative study with a relatively small sample size, we are highly cognizant that our findings in no way speak for all, or even many \#MeToo users. That being said, the data below nonetheless presents an important starting point for researchers wishing to explore the experiential accounts of contemporary western digital feminism. We recognize the ways further attention is needed to collect the voices of traditionally marginalized groups such as gender non-confirming communities, LBGTQ+, and BAME women, for whom, despite the visibility of \#MeToo, are often silenced, unrecognized or ignored (see Cole, 2015; Geisler, 2018).

\section{"The world should know that we face harassment everywhere": Being Moved into Action}

To understand the experience of participants, one of the key questions we asked in both the open-ended web survey and follow-up interviews was why they participated in the \#MeToo movement. Here, our participants shared a variety of reasons for taking part, from a desire to 
educate boys and men on the harms of sexual violence ("To raise awareness of the blindness to toxic masculinity"), to make rape culture visible ("The world should know that we face harassment everywhere"); to expressing solidarity with others ("Because.... metoo....We need to support each other, or else we are all alone against it"); and to locate sexual violence as a political issue ("I recognized the potential to use a deceptively simple message to illustrate to society writ large that sexism/misogyny/violence against women is not an individual problem or isolated issue but a systemic/ubiquitous one"). What emerged in many of these responses was the way many were seemingly compelled to add their voice and often literally felt "moved" into doing so from outrage, anger, and a desire to be heard and spark social change. These motivations fit well with the work of social movement scholars who have been influenced by the "affective turn" in social media scholarship (Papacharissi, 2015), and who recognize the ways anger and outrage can be productive emotions when trying to instigate social change and are critical in forging "affective counter publics" (McCcosker, 2015); what we have elsewhere called "networked feminist counter publics" (Mendes et al., 2019). These counter publics are both public in some senses that they are online and visible but also "intimate" (Dobson et al., 2018) and forged through feelings of intimacy such as personal sharing, meaningful resonance with others, and mutual recognition common to feminist consciousness raising (see Mendes et al., 2019). They are counter publics also because they are resistant subcultures that go against social norms and forming new languages, vocabularies and communicative modes of vernaculars of engagement and resistance (see also Ringrose \& Mendes, forthcoming).

Social movement research suggests most people will only become "open to the possibility of protest" in response to a "moral shock" or something truly upsetting or disturbing (Jasper, 1997) and this idea of critical breaks and ruptures has also informed research on feminist pedagogy and learning (Ringrose, 2007). More recently, we've found 
Sara Ahmed's concept of a "feminist snap" or critical breaking point useful for understanding participant involvement in affective ways that consider sudden jolts of awareness that are significant and "glow" for participants in particular ways (Renold \& Ringrose, 2014). As one woman shared after joining the \#MeToo hashtag: "It felt like it was the tipping point for me. I could no longer just stand by and do nothing." We also witnessed this at many points in our observations of posts in our personal network - a compulsion to respond, that was experienced in a range of ways. This affective sense of an inability to remain silent - or an obligation to speak and join in was reiterated throughout the surveys and follow-up interviews, and importantly, was experienced in positive but complex and conflicting ways. \#MeToo therefore represented a "breaking point" for some, and this was articulated in a range of ways. For example, one spoke about how she joined because of an "inner sense of conviction" that was sparked by public, networked posts. Still another wrote about how she felt she had a "moral obligation to speak against a culture of violence toward women." Providing no further context, one participant simply stated that she felt at that moment that sharing her story "was the right thing to do." The prevalence of coming or standing together discourses demonstrate how adding their voices to \#MeToo was not simply about individual empowerment, but was done because of the recognition that "nothing will change until we act collectively." These posts are temporally marked by sense of urgency and immediacy, which are generated via a sense of an avalanche of responses and chiming in with a wave of discussion.

Understanding more about the motivations and feelings about participants' responses helps to challenge critiques that movements such as \#MeToo are simply narcissistic endeavours used to attain a supposedly "coveted status" of victimhood (Will, 2014). Instead, these movements demonstrate how the public creatively use digital technologies to build networks of feminist solidarity, support and identity (see Fileborn, 2017; Loney-Howes, 
2018; Mendes et al., 2019). Rather than simply joining into a celebrity driven movement to gain visibility and attention, as a range of conservative news media detractors have positioned these debates (Reestorff, 2018), \#MeToo could be regarded as enabling the "construction of knowledge, communities and identities" which has long played a central role in feminist practice (Mohanty, 2003: 528). Furthermore, these practices simultaneously focus on "individual and collective experiences of oppression and exploitation and of struggle and resistance" (Mohanty, 2003: 522). We see this reflected with one participant, who shared how seeing others open themselves up and "putting themselves out there, made me want to do the same thing and join in in the movement." In this sense, many articulated how adding their voice to \#MeToo was about more than simply sharing an individual experience, but about simultaneously building a political analysis of structural violence (Drueke \& Zobl, 2016) and wider communities of care.

Two important elements needed to build counter publics, which operate also as communities of care, are practices of listening and recognition. Whilst some may be doubtful that this type of community is possible in the capitalised and profit driven social media environments such as Twitter (Dean, 2009) we argue that caring relations do emerge out of these platforms. Leah Bassel (2017) has discussed the importance of listening as a political project and how it can be a crucial form of recognition "that counters vicious exclusions that combine race, gender, class and means of rendering people socially abject (Tyler 2013) and...unheard" (6). Although women have been speaking out against sexual violence for decades (see Loney-Howes, this collection; Serisier, 2007), the difference with \#MeToo as a networked movement across continents isn't that the silence has finally been broken, but due to perhaps volume and mass of response the wider public are beginning to listen and take seriously what (some) victims are saying. There is a multi-pronged dynamic where both the tactics and modes of communicating are changing, but also these new strategies are enabling 
recognition of their stories. The potential of having experience recognized by others using the hashtag was particularly important for some participants, given the shame, stigma and disbelief levelled towards those who disclose experiences of sexual violence. This is the result of a wider rape culture, which normalises sexual violence and has a whole repertoire of discourses to blame victims rather than perpetrators (see Alcoff, 2018). One participant explained that sharing her story to \#MeToo was her way of countering the ways she had been "silenced and ashamed about my own experience." Presumably it was the recognition of her experience that helped to counter shame experienced through the forced secrecy and silence of victims in rape culture climates. In this sense, some participants deliberately used the hashtag to take control over their own storytelling and in doing so, challenge dominant "scripts" around sexual violence, particularly those which blame the victim (see LoneyHowes 2018).

Yet, while it is true that survivors are more likely to be listened to and heard than perhaps ever before, not everyone is likely to have their experience recognized, believed or supported in equal measures (see Fileborn, 2017; Loney-Howes, 2018; Mendes et al., forthcoming). To date, scholars have highlighted how diversity continues to remain a problem within (popular) feminist digital spaces, which are often dominated by white, middle-class, cisgendered women (Fileborn, 2017; Fotopoulou, 2016; Kagal, Cowan \& Jawad; Ryan, this collection). We needn't look beyond the \#MeToo movement for evidence of this. As stated in the Introductory Chapter, despite originally being coined by African American activist Tarana Burke in 2006, the widespread and systemic nature of sexual violence was not recognized until a white, Hollywood actress took up the cause. Some of our participants demonstrated an awareness of the role power and privilege played in disclosing experiences of sexual violence, using \#MeToo as a unique opportunity to bring often hidden experiences to the mainstream. Lisa, a 30-year-old queer doctoral student in the UK 
explained in her interview that she used \#MeToo to share her experience of sexual violence in gay clubs both because she wanted to raise visibility of violence in those spaces, but also because as a queer woman, she wanted her experiences "to be counted." In this sense, Lisa seeks to discursively challenge entrenched rape myths which render LGBTQ+ communities as unrapeable, or as unworthy or less understandable as legitimate victims in a heteronormative context (see also Guadalupe-Diaz, 2015; Ison, this collection).

And while anyone who shares their experiences of sexual violence online risks having their "testimony contested or challenged, overlooked, or dismissed" (Loney-Howes, 2018: 45) - what Loney-Howes terms "negative witnessing" (28) - scholars have noted the ways this is particularly true for gender non-conforming individuals, members of the LGBTQ+ communities, those who challenge standards of perceived feminine "respectability" and “credibility" and whose experiences challenge traditional rape scripts (see Mendes et al., forthcoming). As a result, while we celebrate the broader visibility \#MeToo brings to sexual violence, we are aware that its uptake and potential is simultaneously "problematic and limited" (Fileborn, 2017: 1485).

\section{An Easy, Banal or "Low Intensity" Form of Activism?}

In recent years, there have been many critiques of the supposedly easy, banal and low intensive nature of digital engagement (see Gladwell, 2010; Morozov, 2011). Being dismissed as "meaningless" forms of "armchair activism" "slacktivism," or "clicktivism," some scholars and pundits alike ignore very real differences between forms of online activism, or the emotional and affective labour spent participating in a hashtag such as \#MeToo. As Papacharissi (2016) argued:

We assume that social media use will have the same results for all types of movements or publics - it does not. There are similarities, but there are also important 
differences in how the digital aspect of a movement unfolds online, and across different platforms. (312)

As quotes from our participants have already shown, rather than being "easy" or low-level, many articulated the various challenges and difficulties they experienced in the run-up and aftermath of participating in \#MeToo. Several described the experience as "traumatic" and described a powerful range of emotions, from anger, outrage, fear and anxiety - which were not simply contained to digital spaces, but spilled over from online practices to offline contexts. In this sense, our research contributes to a growing body of scholarship that problematizes simplistic binaries between "online" and "offline" life (see Jensen 2012; Ringrose \& Harvey, 2017) and showcases the slippage of experiences across domains. Exploring affect is one way to show the impact of experiences of digital activism in ways that are not containable to online engagements.

Take the experiences of Britt, a 35-year-old Dutch woman, who explained how she first saw news of \#MeToo on Facebook, but took two days before she added her story. As she recalled, she only participated in the movement after being "seriously angry" about public conversations around the hashtag, reading comments about how women were "exaggerating, and that the movement had gone too far" and that "one couldn't even smile at a woman without it being taken out of context." Sharing her story thus served as a way to "talk back" (hooks, 1989) to those who "weren't understanding” the hashtag, or who dismissed experiences of street harassment as trivial. Drawing from Sara Ahmed (2014, 2017), we can see Britt's response as that of a wilful, disobedient subject, who enacts the figure of the "feminist killjoy" (Ahmed, 2010) by refusing to remain silenced or allow these experiences to be dismissed. This is also a powerful example of how the feminist counter public emerges through an affective politics of support and refutation through targeted posts, debate and 
prolonged combative engagement with those who are disputing the severity and implications of gender and sexual violence.

Yet despite feeling very angry about public response to the movement, Britt did not immediately share her own personal experiences on \#MeToo. As she explained:

[I]t took me two days to write my story. So, I wrote it for myself first. I wrote it on my phone in the notes app on iPhone...I was in a hotel with my husband and I was reading about \#MeToo online and it was midnight, and I couldn't sleep because I kept thinking about it, and thinking about my own experiences. And how I deal with things is I write it down, and then it's out. And so, I did that to get it off my chest and then I started reading more Facebook posts, and that night I read my post again and I edited it again, and after writing it I showed my husband first. And that was an emotional moment because of the stories and hearing all about it... After I showed it to him, I sent it to my brother and said should I put this on Facebook? And he said yes.

It is clear from the excerpt above that contributing her story to the \#MeToo hashtag was neither meaningless, easy, nor banal for Britt, who not only agonized for several days over whether to share her story, seeking encouragement from her husband and family, but spent time "curating" it (Fileborn, 2018). This curation is a complex online-offline negotiation where she clears her story with the immediate men in her intimate life - her husband and brother. It is important that it is a supportive offline family context that enables her post, which may not be possible if these conditions were different. Indeed, it is striking that she sought their permission or acceptance in order to proceed. This alerts us to the complex gendered power dynamics at work in engaging with and using \#MeToo and digital activism against sexual violence and the difficulty of personal disclosure (see also Mendes et al., 
2019). Hers is just one example of why scholars must attend not only to the unique formations of various digital feminist campaigns (Papacharissi, 2016), but to the highly complex, differentiated and varied experiences of those who contribute to them. Drawing from bell hooks (1989), scholars must not forget the way speaking can be a radical act:

When we dare to speak in a liberatory voice, we threaten even those who may initially claim to want our words. In the act of overcoming our fear of speech, of being seen as threatening, in the process of learning to speak as subjects, we participate in the global struggle to end domination. (18)

Indeed, feminist scholars have written about the importance of "discursive activism" and how in the fight to transform power relations and social structures, attention and resources must be spent on speech acts which change the ways people think (see Keller et all, 2018; Mendes, 2015; Shaw, 2012). Thus, we argue it is important to push back against broad claims that digital activism in general, and hashtag activism specifically, is necessarily easy or meaningless simply because it is done online. As we will also show below, the potential of a movement such as \#MeToo can contribute to dramatic personal changes, which are necessarily connected to the possibility of broader social transformations, if we are attentive to the relationship of the affective and the personal and social as entangled in ways that must be mapped out.

\section{The Transformative Potential of \#MeToo}

As we have written about in more detail elsewhere regarding other formations of digital feminist activism (Mendes et al., 2018; Mendes et al., 2019), we are generally optimistic about the power and potential of popular feminist movements such as \#MeToo for bringing 
about "real-world" changes and transforming our participants' lives. From both our wider data set and that focusing specifically on \#MeToo, participants shared a range of changes in their everyday lives, actions, mindsets and beliefs. While some of the changes discussed are tangible, such as one victim who went on to report her rape to her campus police, many are seemingly ephemeral, take place on micro-levels, and are difficult to measure. These include the ways participants became "more vocal" in calling out sexist practices and behaviours, to another who ended a friendship with someone because of the way he harassed women.

Indeed, from participants' perspectives, the vast majority were adamant that \#MeToo has had a significant impact, either on themselves, people in their lives, or society more broadly. As one participant wrote: "I think it has (at least on a personal level) and will do in the future." Many survey respondents used exclamation marks to further emphasize their agreement with this statement ("Yes! It means that for the first time we generally assume that victims tell the truth"), or words such as "definitely" or "I know it has." While many survey participants simply affirmed that \#MeToo had some form of impact, others provided more details, such as the ways it has opened up new conversations: "Yes, for example we talked about it in my family, both with my male and female family members." Another noted how it has made people become "more conscious in work environments." Several participants also mentioned how \#MeToo has resulted in widespread conversations, protests, and discussion about the need for consent and better sex education in the curriculum. Although it's unclear what these conversations will lead to, consciousness-raising has always remained an important tenet of feminist activism for decades and has been shown to have material consequences on women's lives (Shaw, 2012).

While the impact discussed above may be taking place at a micro level and may not be easily quantified, other participants identified measurable results. One participant in Sweden credited \#MeToo for spurring forward "new laws regarding consent. I think laws in 
turn will effect people's viewpoints.” Another participant from Northern Ireland noted the ways \#MeToo inspired many to take part in "mass protests" and "subsequent discussions to alter rape laws and consent education." One Australian participant shared: "Certainly, in Australia we've seen the introduction of NOW, to provide legal support to women who've experienced sexual harassment in the workplace (similar to the US Time's Up campaign).” Significantly, our survey was live just as Bill Cosby was found guilty for aggravated sexual assault, and several participants specifically identified this verdict as tangible evidence of change. As one wrote: "Yes. Look at Cosby verdict. I believe that's influenced by \#metoo."

While we are heartened to see participants identifying changes, it would be disingenuous to claim all participants were optimistic about \#MeToo's impact or potential, as some doubted its ability to foster longer-term, broader social or cultural change. Yet even amongst these responses, there were clear articulations of hope that it would, with variations of "I hope so but I'm not sure." Here, many noted that while \#MeToo had started very important conversations around sexual violence, consent and rape culture, "there's a very long way yet to go." Rather than looking forward to the future, several looked back to the past noting, "I hope so, although if the past is anything to go by, I'm not overly optimistic. But I hope I'm wrong.” Another participant articulated the importance of cultural change, noting how this is "harder than to instil than legislation" which is why it is vital that the public "continue to talk about it." As we have also made clear, it is this intimate counter public (Dobson et al., 2018) experience of talking, sharing and creating shared awareness and the capacity for dissent that is so salient in understanding the processes of social transformation. Our affective lens is important for enabling a discussion of these micro politics of experiences of digital activism, which transform individuals and possibly their relational contexts in profound ways as yet uncharted.

\section{Conclusion}


Drawing from empirical data gathered from 117 real-life \#MeToo users via surveys and semi-structured interviews, this chapter explored some of the motivations and experiences of participating in this digital feminist phenomenon. Influenced by the affective turn in scholarship, the chapter sought to demonstrate how one "deceptively simple message" moved many into participation. Participants shared a range of reasons why they added their voice to the hashtag - from a sense of anger and outrage at the pervasiveness of rape culture, to a desire to challenge rape myths that deny recognition for many victims, to a desire to build structural analysis of sexual violence, to generating communities of care. Throughout the chapter, we have shown how the varied reasons for contributing to and joining in the hashtag are the flesh and bones of an emergent feminist counter public. Although these tangible experiences have not yet been charted, they show the force and relevance of these experiences in our participants' lives. In a sense, the chapter highlights why it is so important not merely to investigate what people are contributing to the hashtag, but their practices and experiences of participation. As scholars, we must also be mindful of which voices are absent, and in this chapter we have attempted to draw attention to issues of power and privilege which shape the ways certain testimonies are listened to, ignored or (dis)believed. Further work is necessary to theorize the limits and constraints of forging feminist counter publics in terms of what discourses and experiences fit, or are recognized and legitimated in relation to sexual violence, and which are not (Powell, 2015).

Moreover, in privileging the voices and experiences of our participants, our chapter is also strongly challenging problematic generalizations that engaging in digital activism is easy, banal, or a form of "low-intensity" activism (Gladwell, 2010; Morozov, 2011), and instead highlight the affectively charged, often traumatic nature of this work. Digital feminist campaigns such as \#MeToo have transformed many of our participants' lives in both tangible and hard-to-measure ways, but fleshing out experience moves us to a different register in 
understanding how social transformation happens. Finally, we also strongly refute the notion that participating in \#MeToo is simply about empowering the self in any individualising way - as many of our participants stressed that its power lies firmly in the collective act of speaking out against sexual violence and knowing there was "strength in numbers." We must firmly understand \#MeToo as a digitally networked phenomena which has enabled mass participation, connectivity and consciousness raising. Therefore, while \#MeToo alone will not end sexual violence, it is part of the combat and battle that chips away at normative gender and sexual power relations offering new possibilities; it therefore plays a critically important role in making visible the "structural connections of sexism and violence" (Drueke and Zobl, 2016: 50) which are becoming increasingly harder to ignore.

\section{References:}

Ahmed, S. (2004) The Cultural Politics of Emotion. Edinburgh: Edinburgh University Press. Ahmed, S. (2010) Killing Joy: Feminism and the History of Happiness. Signs 35(3): 571-94. Ahmed, S. (2017) Living a Feminist Life. Durham and London: Duke University Press. Alcoff, L.M. (2018) Rape and Resistance. London: Polity Press.

Bassel, L. (2017) The Politics of Listening: Possibilities and Challenges for Democratic Life. Basingstoke: Palgrave Macmillan.

Cole, K.K. (2015) “'It's Like She's Eager to be Verbally Abused': Twitter, Trolls, and (En)Gendering Disciplinary Rhetoric.” Feminist Media Studies 15(2): 356-358.

Dean, J. (2009) Democracy and Other Neoliberal Fantasies. Durham: Duke University Press.

Dobson, A., Robards, B. \& Carah, N. (2018) Digital Intimate Publics \& Social Media, London: Palgrave.

Drueke, R. \& Zobl, E. (2016) “Online feminist protest against sexism: the German-language hashtag \#aufschrei'”, Feminist Media Studies, 16(1): 35-54. 
Fischer, M. (2016) “\#Free_CeCe: the material convergence of social media activism”, Feminist Media Studies, 16:5, 755-771

Fileborn, B. (2017) “Justice 2.0: Street harassment victims' use of social media and online activism as sites of informal justice”, British Journal of Criminology, 57: 1482-1501.

Fileborn, B. (2018) "Naming the Unspeakable Harm of Street Harassment: A Survey-Based Examination of Disclosure Practices", Violence Against Women. DOI:10.1177/1077801218768709

Fotopoulou, A. (2016) Feminist Activism and Digital Networks: Between Empowerment and Vulnerability. Basingstoke: Palgrave Macmillan

Geisler, C. (2018) "The Voices of \#MeToo: From Grassroots Activism to a Viral Roar " International Communication Association, Prague. 24-28 May.

Gray, M. (2009) Out in the Country: Youth, Media, and Queer Visibility in Rural America. New York: NYU Press.

Guadalupe-Diaz, X (2015) "Same Sex Victimization and the LGBTQ Community." In Richards, T.N \& Marcum, C.D. (eds) Sexual Victimization: Then and Now. Thousand Oaks, London \& New Delhi: Sage. 173-192.

hooks, b. (1989) Talking back: Thinking feminist, thinking black. Toronto: Between the Lines.

Jasper, JM (1997) The Art of Moral Protest: Culture, Biography and Creativity in Social Movements. Chicago and London: University of Chicago Press. 
Joffe, H. (2012) “Thematic Analysis.” In Qualitative Research Methods in Mental Health and Psychotherapy: A Guide for Students, edited by David Harper and Andrew Thompson , 209-224. Malden \& Oxford: Wiley-Blackwell Press.

Keller, J., Mendes, K. \& Ringrose, J. (2018) “Speaking Unspeakable Things: Documenting digital feminist responses to rape culture”, Journal of Gender Studies, 27(1): 22-36.

Loney-Howes, R. (2015) "Beyond the spectacle of suffering: representations of rape in online anti-rape activism", Outskirts: Feminism Along the Edge, 33: 1-17.

Loney-Howes, R. (2018) “Shifting the Rape Script: 'Coming Out' Online as Rape”, Frontiers: A Journal of Women's Studies, 39(2): 26-57.

Mendes, K. (2015) SlutWalk: Feminism, activism \& media. Basingstoke: Palgrave Macmillan.

Mendes, K., Ringrose, J., and Keller, J. (2018) “\#MeToo and the Promise and Pitfalls of challenging rape culture through Digital Feminist Activism", European Journal of Women's Studies, 25(2): 236-246.

Mendes, K, Ringrose, J., and Keller, J (2019) Digital Feminist Activism: Girls and Women Fight Back Against Rape Culture. Oxford: Oxford University Press.

McCosker, A. (2015) "Social Media Activism at the Margins: Managing Visibility, Voice and Vitality Affects", Social Media + Society, 1(2), https:// doi.org/ 10.1177/ 2056305115605860.

Mohanty, C.T. (2003) “"Under Western Eyes” Revisited: Feminist Solidarity through Anticapitalist Struggles', Signs, 28(2), 499-535 
O’Neil, T. (2018) “Today I Speak”: Exploring How VictimSurvivors Use Reddit. International Journal for Crime, Justice and Social Democracy, 7(1): 44-59.

Powell, A. (2015) “Seeking Rape Justice: Formal and Informal Responses to Sexual Violence through Technosocial Counter- Publics”, Theoretical Criminology 19(4): 571- 588.

Papacharissi, Zizi. 2015. Affective Politics: Sentiment, Technology, and Politics. Oxford: Oxford University Press.

Papacharissi, Z. (2016) “Affective publics and structures of storytelling: sentiment, events and mediality", Information, Communication \& Society, 19(3): 307-24

Ringrose, J. \& Mendes, K. (2018) “Mediated Affect \& Feminist Solidarity: Teens' using Twitter to challenge 'rape culture' in and around school." In Editors: Tony Sampson, Darren Ellis and Stephen Maddison, Affect and Social Media, London: Rowman and Littlefield.

Ringrose, J. (2007) “Successful girls? Complicating post-feminist, neoliberal discourses of educational achievement and gender equality." Gender and Education, 19 (4), 471 489.

Ringrose, J. and Renold, E. (2014) ““F**k rape!’ Mapping Affective Intensities in a Feminist Research Assemblage." Qualitative Inquiry 20 (6): 772-780.

Serisier, T. (2007). Speaking out against rape: feminist (her)stories and anti-rape politics. Lilith. 16: 84-95

Shaw, F. (2012) “"Hottest 100 Women”: Cross-Platform Discursive Activism in Feminist Blogging Networks', Australia Feminist Studies, 27(74), 373-87. 
Will, G. (2014) “Colleges become the victims of progressivism”, Washington Post, 6 June. Available at: https://www.washingtonpost.com/gdprconsent $/$ ?destination=\%2fopinions $\% 2$ fgeorge-will-college-become-the-victims-ofprogressivism\%2f2014\%2f06\%2f06\%2fe90e73b4-eb50-11e3-9f5c9075d5508f0a_allComments.html\%3f\&utm_term=.3f1b4ecfcbbd 